\title{
Sustainable Development of Prefabricated Buildings from the Perspective of Green Supply Chain Management
}

\author{
Yanli Chen \\ Architectural Engineering Institute, Xinyang Vocational and Technical College, Xinyang, Henan, \\ China
}

\begin{abstract}
As a green, environment-friendly, energy-saving and efficient building, prefabricated building has become an important way for the development of building industrialization in China. In this paper, the green supply chain structure model of prefabricated building is constructed from the perspective of green supply chain life cycle, and the evaluation index system of sustainable development of prefabricated building is established. This paper analyzes the whole life of assembly green supply chain and applies hierarchical clustering TOPSIS comprehensive evaluation model to evaluate and identify the key nodes of assembly green supply chain. This provides theoretical support and decision-making basis for green supply chain optimization management of prefabricated buildings. At the same time, this paper puts forward some suggestions for the operation of the key links of the prefabricated green supply chain, and realizes the green sustainable management of the whole life cycle of the prefabricated building supply chain. The test results show that this method can promote the sustainable development of prefabricated buildings.
\end{abstract}

Keywords: Prefabricated building, green supply chain, life cycle, hierarchical clustering model.

\section{Introduction}

At present, China's central and local governments at all levels are taking positive measures to promote the research and application of prefabricated buildings. However, due to the low maturity of the prefabricated industry chain, the asymmetric information of the participants of prefabricated buildings, and the lack of the whole process management of prefabricated buildings, the sustainable and industrialized development of prefabricated buildings in China is hindered. Therefore, in order to promote the sustainable development and application of prefabricated buildings, it is necessary to evaluate the sustainability of prefabricated buildings scientifically.

At present, the research on the sustainable development of prefabricated buildings has become a hot spot and mainstream in academic circles. In terms of foreign research, some scholars [1] analyzed the sustainability of prefabricated buildings from the perspective of designers, manufacturers, suppliers and other stakeholders. Some scholars [2] analyzed the advantages and disadvantages of prefabricated buildings from the perspective of environmental sustainability and resources, and identified the obstacles to the development of green prefabricated buildings. In terms of domestic research, Teng [3] constructed the evaluation index system of sustainable development of prefabricated buildings from four aspects of economy, resource consumption, environment and society, and evaluated the sustainable development level of prefabricated buildings by using grey clustering model. Zhang and Wang [4-5] established the evaluation index of sustainable development of prefabricated buildings from the perspective of the whole life cycle from the four aspects of economy, environment, society and resources, and verified the effectiveness of the evaluation system through comparative analysis. Based on the characteristics of factory production of prefabricated buildings, some scholars have studied the sustainability of prefabricated buildings from the perspective of supply chain. Some scholars have studied and analyzed the influence mechanism of key management behaviors of supply chain leaders on the sustainable development competitive advantage of prefabricated buildings.

ISSN: 0010-8189 
Throughout the existing research results, most scholars or from the perspective of economic, social, environmental, resource and other basic sustainable characteristics of prefabricated building for sustainable development research, or one-sided from a certain stage of prefabricated building for prefabricated building sustainability analysis. Few scholars combine green supply chain with prefabricated building to study the sustainability of prefabricated building from the perspective of supply chain integrity. Prefabricated building adopts factory mode to produce prefabricated components, which is similar to the production characteristics of manufacturing industry. Its core is integration, and each stage of its production is closely linked. Problems in any stage or link will affect the delivery of the whole prefabricated building project. The dynamic operation of green supply chain based on the whole process environmental management mode can provide a good implementation path for the sustainable development and utilization of prefabricated buildings. The combination of prefabricated building and green supply chain has the characteristics of long supply chain, involving many enterprises, many life cycle stages, and high requirements of supply chain integrity and coordination. How to improve the sustainability of prefabricated buildings through the whole life cycle management of prefabricated green supply chain has become the focus and difficulty of current research. Based on this problem, this paper constructs the green supply chain structure model and sustainable development system of prefabricated buildings from the perspective of green supply chain life cycle, identifies the key nodes of green supply chain of prefabricated buildings, and puts forward specific suggestions, so as to provide reference for green supply chain life cycle management and sustainable development of prefabricated buildings.

\section{Integration of prefabricated building technology}

(1) Development status of prefabricated building abroad

In the process of developing prefabricated building, Japan has established a perfect system. After continuously exploring the prefabricated technology system, the KsI building system (urban regeneration framework + filled residential building system) is formed, as shown in Figure 1. Prefabricated buildings have accounted for more than $50 \%$ of the market. In the process of developing prefabricated buildings in the United States, low rise wood structure and light steel structure residential buildings are the main ones, and the market mechanism is the main one [6]. As early as 1976, the design, construction, energy saving and durability of prefabricated buildings were standardized [7-9]. At present, assembly parts can be selected on demand through the standard catalog. In addition, Singapore, Britain, Sweden and other countries have formed a perfect system in the development process of prefabricated buildings, and precast concrete members have been widely used in civil and industrial buildings.
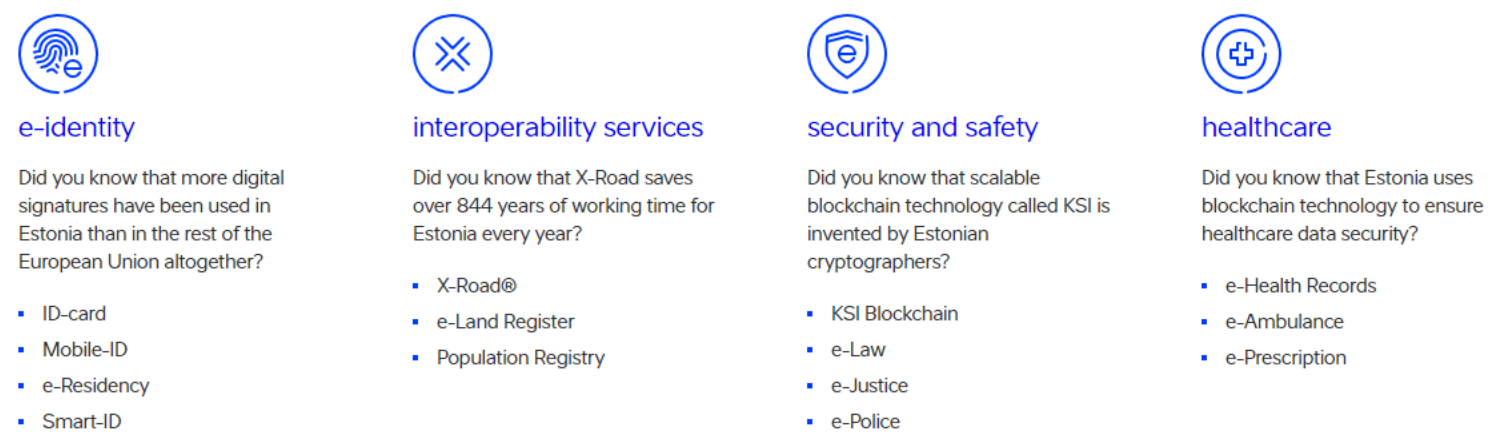

ISSN: 0010-8189 


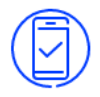

e-governance

Did you know that $99 \%$ of public services are available to citizens as e-services?

- Government Cloud

- Data Embassy

- i-Voting

- e-Cabinet

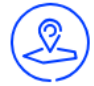

mobility services

Did you know that self-driven vehicles have been allowed to drive on public roads in Estonia since 2017?

- Intelligent Transportation Systems

- Mobile Parking

- Border Queue Management

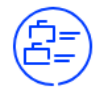

business and finance

Did you know that you can establish a company in Estonia just in 3 hours?

- e-Tax

- e-Banking

- e-Business Register

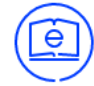

education and research

Did you know that twice as many students pursue IT careers in

Estonia than the average in other $\mathrm{OECD}$ countries?

- Estonian Education Information System

- eKool and Stuudium

- Estonian Research Information

System

- e-Schoolbag

- Other e-school solutions

Fig 1 KSI building system

(2) Development status of prefabricated building in China

Since the 1990s, China has proposed the development of prefabricated architecture [10]. In recent years, with the continuous introduction of policies to promote prefabricated buildings, cities such as Beijing, Shanghai, Shenzhen and Chengdu successively require the use of prefabricated components in housing construction. With policy support and market orientation, developers and construction enterprises have begun to participate in the research and implementation of prefabricated construction technology.

\section{Life cycle management based on sustainable development of prefabricated buildings}

\section{A. Architecture and process of sustainable development of prefabricated buildings}

BIM has eight characteristics: information completeness, information relevance, information consistency, visualization, coordination, simulation, optimization and graphing. So that the construction unit, design unit, construction unit, supervision unit and other project participants can share the same building information model on the same platform, which is conducive to the visualization and fine construction of the project.

For construction projects, the whole life cycle includes design, production, construction, operation and maintenance, as shown in Figure 2. In the management of the whole life cycle, information management is its important core content, that is, to establish an information model, to integrate the design, construction, operation and management, to avoid information errors in the process of communication and communication, to reduce the quality of management, and to affect the overall quality of construction projects. In the whole life cycle management, the content of management mainly includes the following two aspects:

(1) Realize information management and information engineering of construction engineering, improve project quality, construction efficiency and profitability;

(2) Manage all information generated during the construction of the construction project.

ISSN: 0010-8189 


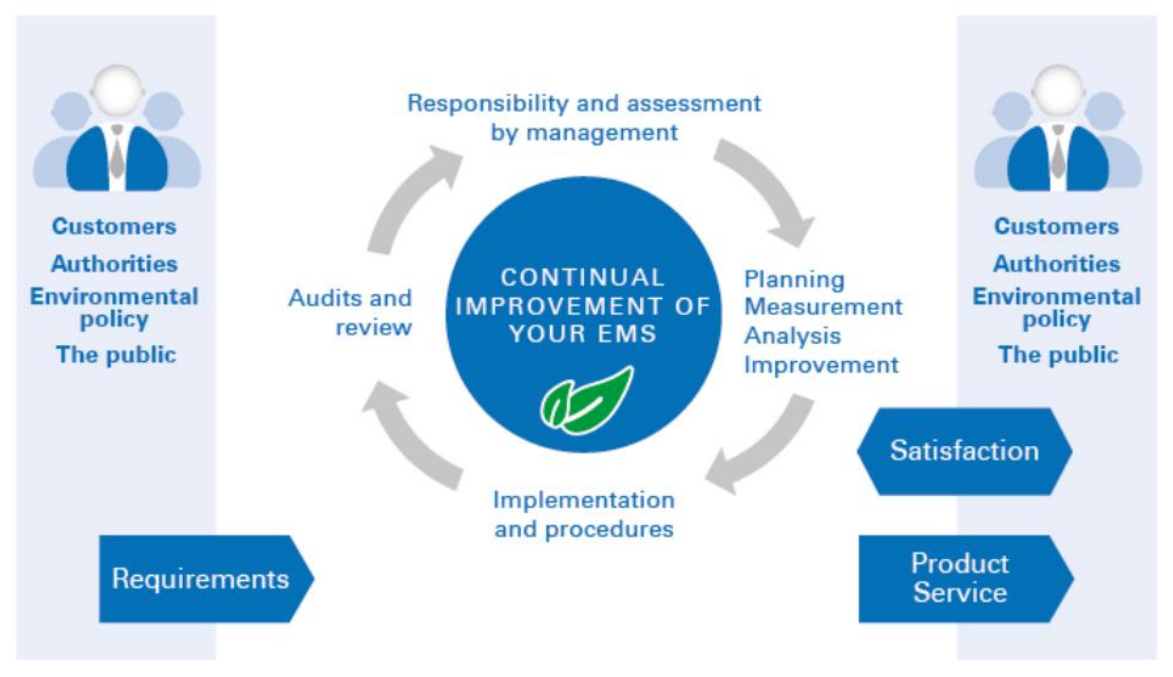

Fig 2: The whole life cycle information management

The architecture of BIM management system, as shown in Figure 3, can be divided into:

(1) Model organization

In order to apply BIM to the whole life cycle management of prefabricated buildings, it is necessary to build the building information model first, and divide the model into different types according to the specialty. For example, taking the "component" of construction engineering as the basic unit, the relevant information of "component" is composed of "set", and the "container" in it is to store all "sets" in the same file. In BIM management system, the role of "file" is to connect different models together, improve the flexibility of model assembly, provide convenience for the management of the whole life cycle, and it is also the basis of realizing the goal of the whole life cycle management.

(2) Directory structure

Based on the splitting of building information model, dozens or even hundreds of different but closely related model files will be generated in the system. In order to improve the efficiency of management, after building the information model, all the files should be compiled into a retrievable directory, which is easy to refer to when calling. When organizing the catalog, it should be determined according to the project scale and project type, but its basic principle is to organize it according to the splitting model. Since all links of construction engineering from design to construction are constantly changing, it is necessary to take this change into consideration, and divide the contents into different states, such as "archiving", "publishing", "information sharing" and "construction process". Only by implementing the above work ideas and methods can we provide accurate document catalogue in the completion and delivery stage.

(3) File naming

Usually, institutions or enterprises have specific rules on file naming, which can refer to or refer to European and American standards, such as AEC standard, AIA standard, etc. However, in order to ensure that the owners can clearly and intuitively grasp the basic content of the document, a unified standard belonging to BIM management should be formulated to ensure the standardization and systematization of the file name.

ISSN: 0010-8189 


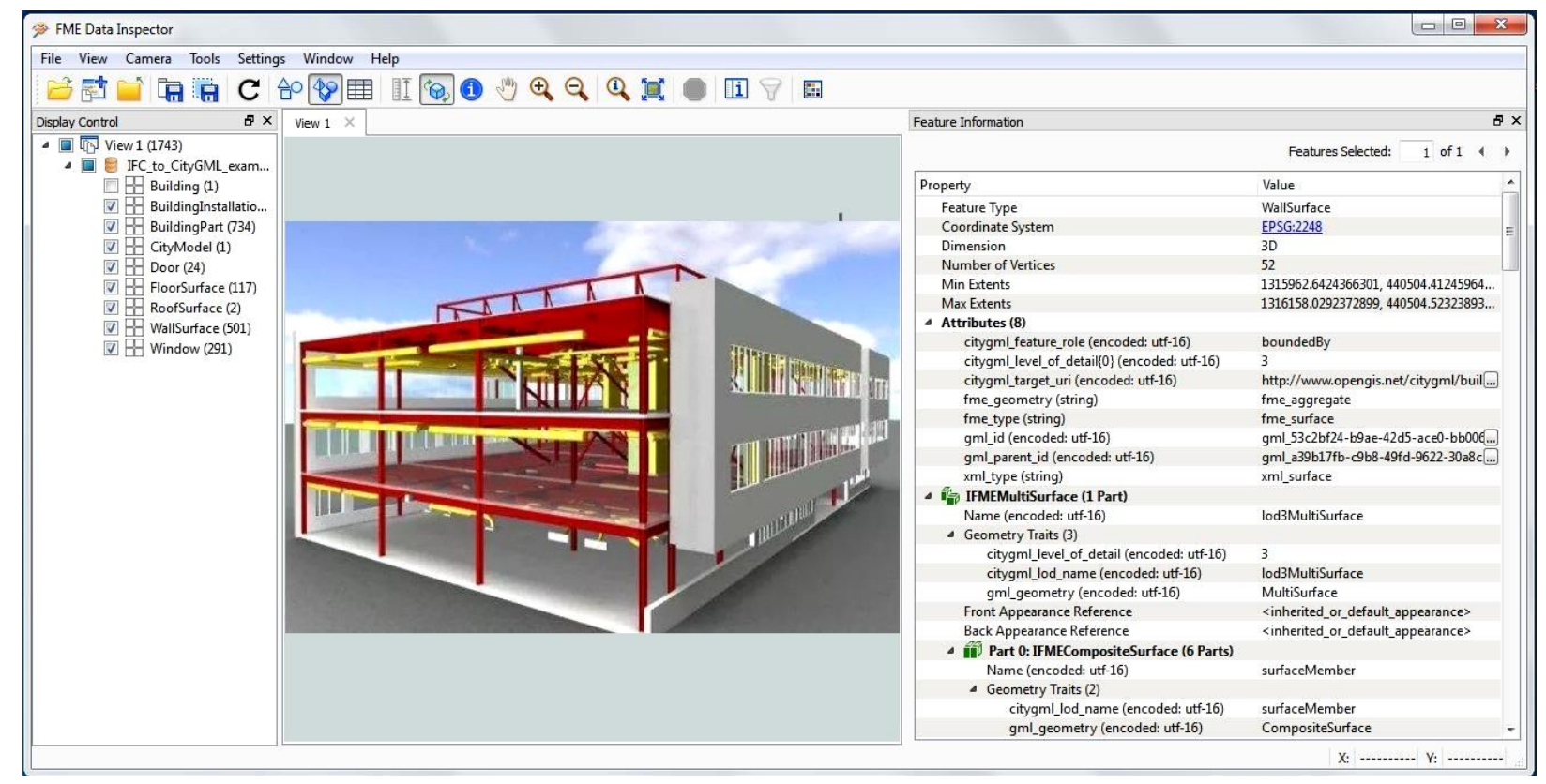

Fig 3: The architecture of BIM management system

\section{B. Life cycle management of prefabricated building}

Life cycle management process is shown in Figure 4. Four aspects are included in this stage:

(1) Application of project planning stage

The analysis and selection of analysis site and site selection directly affect the positioning of the project. In the traditional life cycle management, the analysis and selection of site are influenced by subjective factors, which can not deal with information in a scientific and effective way, resulting in insufficient quantitative analysis of site, and then affect the project positioning. After applying BIM Technology to the site analysis and selection of prefabricated construction engineering, it can take the geographic information technology as the basis to simulate the process of site construction, especially when dealing with the earth rock balance and site boundary problems, which can more accurately analyze the rationality of the site and ensure the accurate positioning of Construction Engineering.

(2) Drawing and modeling

In the completed BIM model, each image source represents a specific meaning, including space size, metal materials, etc. If the parameters of a component are changed in the management work, the related components will usually change, and then the model modification can be fully controlled. Using BIM Technology model can accurately simulate the difficulties in construction, such as new structures, new forms and nodes. Once problems are found in the engineering design, the scheme can be optimized at the first time to fundamentally guarantee the quality of prefabricated buildings. In addition, based on BIM, designers of construction engineering can use its visualization function to discuss design scheme with owners, construction units and construction suppliers, so as to comprehensively improve management efficiency.

ISSN: 0010-8189 


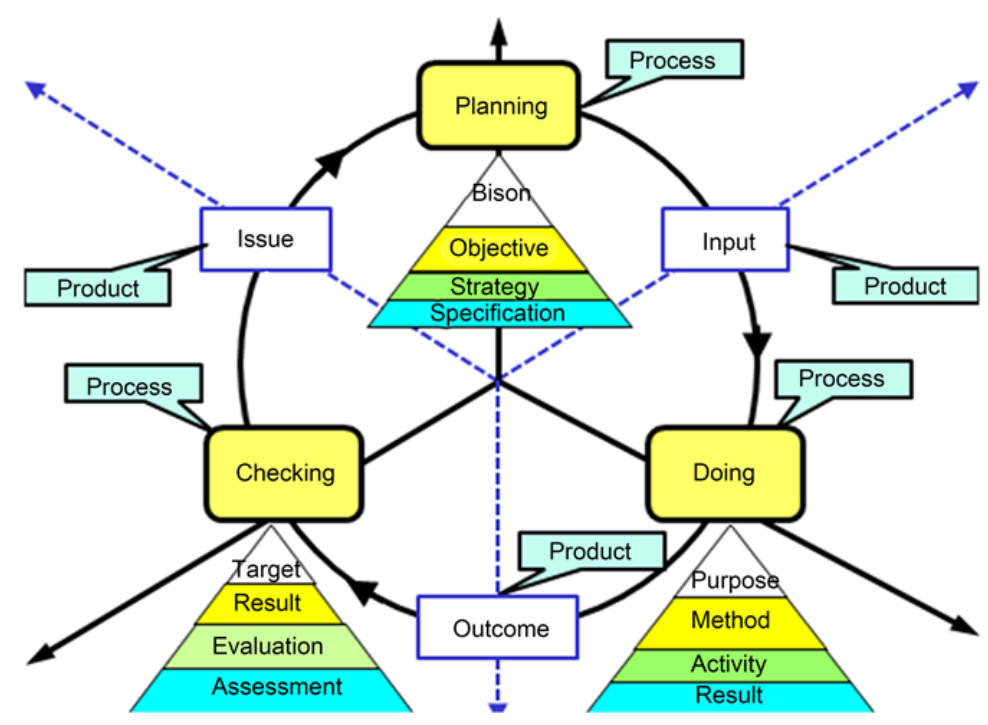

Fig 4: Life cycle management process

(3) Check for design conflicts

In the traditional life cycle management work, the three-dimensional space model is often constructed according to the subjective consciousness of the management personnel, so it is difficult to avoid the human error between construction and design, especially in the pipeline construction link, it is easy to cause the collision between different pipelines due to the lack of in-depth understanding of various pipeline space relations by different professional designers, which affects the construction progress of construction engineering At the same time, it will increase the construction unit cost. In view of such problems, in order to ensure the quality of construction engineering, it is necessary to deepen the design of various professional pipelines. Therefore, the BIM management system can be applied in the project. When designing the project model, the staff can simulate the state of various pipeline construction through the BIM system, so as to analyze the relationship between pipelines. Once the problems are detected, the system will show the specific content and location, so that the staff can modify them in time, and then find out the problems before construction, so as to avoid the delay of completion time And so on.

(4) The construction of the tradition of engineering quantity statistics

Due to the use of CAD software to calculate and construct the relevant building information, it is difficult to automatically complete the quantity statistics, so it usually consumes a lot of labor time to improve. If BIM is applied to construction engineering, the system can automatically integrate the information of component quantities and material types, and managers can consult it at any time. Thus greatly shorten the working time, and can ensure the accuracy of the calculation results, for the prefabricated building cost management, progress management and other work to provide the basis.

\section{Application of Component Production Stage}

In the process of component production, BIM Technology can be combined with RFID technology. RFID is a kind of non-contact automatic identification technology, which can automatically identify the target object and obtain relevant data through radio frequency signal without manual intervention. As a wireless version of bar code, RFID technology has the advantages of waterproof, antimagnetic, high temperature resistance, long service life, large reading distance, encrypted data on the label, larger storage capacity, and easy change of stored information, which is one of the most widely used technologies in the Internet of things. RFID technology is applied to the whole life cycle management of prefabricated buildings, that is, RFID tags are implanted into various prefabricated components, and an independent tag is set for each component, which can provide high

ISSN: 0010-8189 
traceability for component production and management, and strengthen the management of component storage, transportation and hoisting process.

The combination of RFID and BIM Technology can timely extract the parameters (model information in the design stage) required by the production activities, so that the production personnel can carry out the component production according to the specific parameters in the system, and can better ensure the quality of components. Because RFID tags are embedded in each component, the information of production, quality and storage of all components can be transmitted to BIM database to ensure that the components can be used accurately. In a word, the combination of RFID technology and BIM Technology can improve the accuracy of component production, improve the efficiency of component management, and achieve the goal of zero inventory and zero defect management as far as possible. At the same time, in the component production stage, it can also transmit the actual progress of the prefabricated building and related information technology to the subsystem, improve the scientificity and automaticity of the production work, avoid the production problems such as waiting for work and materials, ensure that the production work can meet the construction needs of the construction project, and ensure that the project is completed on time as required.

\section{Conclusion}

The information construction of prefabricated buildings still faces many challenges. First, the development of prefabricated buildings is still dominated by the government, and the atmosphere of market spontaneous promotion and application of prefabricated buildings has not been fully formed. Second, the application of BIM Technology in the construction field is mainly concentrated in the design and construction stage, only a few major projects have entered the BIM operation and maintenance stage, and the popularization level and application depth of BIM Technology are not enough.

At present, the information technology represented by BIM Technology is more and more widely used in the field of construction. However, the application of BIM in the stage of prefabricated building design is much higher than that in the stage of construction and operation and maintenance. In the future, enterprises need to pay more attention to solve the comprehensive application of BIM in the whole life cycle of buildings, increase the systematic research of BIM Technology, and expand the application research combined with other technologies in engineering. The development of China's prefabricated construction industry needs the support and guarantee of policies, gradually realize the promotion of prefabricated construction through market-oriented means, and constantly accumulate relevant professional and technical experience and cultivate professional and technical personnel. At the same time, it is necessary to deeply study and apply BIM Technology to explore the information construction road of prefabricated buildings in line with the law of domestic market development.

\section{References}

[1] Chen Yan, Dai Hongjun, Liu Jing. Framework of Building Information Model in Project Management Information System. Construction Technology, 2008 (02): 9-12

[2] Liu Zhan Sheng, Li Bin, Wang Yang. Application of BIM Technology in Construction Management of Doha Bridge. Construction Technology, 2015 (12): 76-80

[3] Teng Jiaying, Wu Xianguo, Zhai Haizhou. IPD Collaborative Management Framework Based on BIM and Multi-party Contract. Journal of Civil Engineering and Management, 2013, 030 (002): 80-84

[4] Zhang Jianping, Fan Zhe, Wang Yangli. Dynamic Management of Construction Resources and Realtime Cost Monitoring Based on 4D-BIM. Construction Technology, 2011, 40 (002): 225-225

[5] Wang Guangbin, Zhang Yang, Tan Dan. Research on Cost Accounting Theory and Implementation Method of Engineering Project Based on BIM. Progress and Countermeasures of Science and Technology, 2009, 026 (021): 47-49

[6] Yang Zhenqing, Zhang Hong, Zhang Lili. Application of BIM Technology in Mechanical and Electrical Construction. Architectural Technology, 2015, 46 (002): 132-134

[7] Xu Jun, Li Anhong, Liu Houqiang. Application and Risk Analysis of BIM in Railway Industry.

ISSN: 0010-8189 
Journal of Railway Engineering, 2014, 31 (3): 129-133

[8] Ma Shaoxiong, Li Changning, Chen Cunli. Application of BIM Technology in Construction Management of a Project. Construction Technology, 2016 (11): 126-129

[9] Miao Changhua, Fei Haifeng, Qian Xuesong. Optimal Management of Electromechanical Pipeline Installation Based on BIM Technology. Architectural Technology, 2013 (10): 890-893

[10] Li Li, Deng Xueyuan. Construction and Application of BIM Database Based on IFC Standard. Sichuan Architectural Science Research, 2013, 39 (003): 296-301

ISSN: 0010-8189 